\title{
Examining the Impact of Music and Movement Interventions on Transitions and Behavioral Engagement in a First-Grade Classroom
}

\author{
Dr. Alicia Stapp \\ Assistant Professor \\ School of Education \\ University of Mississippi \\ 339 Guyton Hall, University, Mississippi \\ 38677 \\ USA \\ Ms. Bryanna Hall \\ Graduate Student \\ School of Education \\ University of Mississippi \\ University, Mississippi \\ 38677 \\ USA
}

\begin{abstract}
The present study examined a novel approach to decreasing transition times and increasing engagement through music and movement as interventions during transitions. Participants were 21 first-grade students at an elementary school in northwest Mississippi. An experimental design was employed during the four phases of the study, wherein data were collected through a student engagement checklist that provided transition start and stop times, behavioral engagement, and consistency of students' body language and focus after the interventions. Findings indicated that transitions took the least amount of time during phase four when music and movement interventions were utilized. Additionally, engagement increased after both morning and afternoon transitions, and a positive trend in body language and focus emerged across all four phases of the study. Results suggest that music and movement interventions many not only be an effective tool for transitions, but also for improving students' cognitive and behavioral engagement in the classroom.
\end{abstract}

Keywords:music integration, movement integration, transitions, elementary education

\section{Literature Review}

Educational reforms in the United States have placed a considerable amount of emphasis on instructional time for English language arts [ELA] and mathematics in elementary classrooms over the past several decades (Nelson, 2013; Patall et al., 2010). As part of those reforms, assessment policies found within the No Child Left Behind Act (NCLB), and the Every Student Succeeds Act (ESSA) have largely contributed to a narrowing of the curriculum beyond core content areas (David, 2011).With an already over packed curriculum, reduced instruction time for non-tested subjects, and pressure to increase students' academic achievement, particularly in ELA and mathematics, requesting classroom teachers to integrate methodologies such as music and movement may be ineffective if they are not provided with support or opportunities to experience the benefits themselves. Although mandated educational policies may discourage teachers from exploring alternative methods and non-tested subjects in the classroom, examining teachers' perceptions and barriers to such methodologies as music and movement integration may be vital to devising a plan for effectively including it as part of a well-rounded curriculum.

\subsection{Barriers and perceptions of music and movement classroom integration}

Evidence regarding teachers' perceptions of music integration suggests that they do not feel a sense of responsibility for integrating music into the curriculum in the absence of a music specialist (Colwell, 2008). This finding is likely a result of the increased demand for higher standardized test scores, which has led to time constraints that drastically limit the additional content teachers can integrate into their lessons (Colwell, 2008). 
Parallel to these finding, primary teachers' perceptions of a school's responsibility to teach music in the classroom revealed that $96 \%$ of private school teachers believed it was their responsibility, while only $73 \%$ of public school teachers saw it as their responsibility. However, $98 \%$ of all respondents did agree that music is beneficial for children (Fortin, 2013).

Another barrier to music and movement integration is a lack of sufficient program models for both pre- and in-service teachers. Many teachers are not exposed to music and movement during teacher preparation and therefore enter the profession lacking self-efficacy (Myrianthopoulos, 2015). Parks et al. (2007) surveyed over three hundred in-service elementary school teachers to determine their views on incorporating movement into daily instruction. Findings revealed that a majority of classroom teachers infrequently integrated movement in their classrooms. Reasoning for this decision varied, but an increased emphasis on standardized test scores as a reliable indicator of a teacher's effectiveness was frequently noted (Parks et al., 2007). Although more than $75 \%$ of the respondents perceived the positive benefits on children's health, a substantial barrier to implementation was the need for significant support from colleagues and other relevant stakeholders in order to succeed (Parks et al., 2007). Benes et al. (2016) also noted that while teachers are willing to add movement related activities as an instructional strategy, most reported a lack of knowledge as reasoning for not including them in their daily instruction. Accordingly, self-efficacy and lack of training or knowledge were revealed as critical barriers to integration of music and movement in the classroom.

\subsection{Benefits of music integration}

\subsubsection{Academic achievement.}

Despite the barriers of music and movement integration the benefits should not be ignored. One of the central benefits revealed by multiple research studiesis the impact of music integration on academic achievement in ELA (Cole \& Boykin, 2008; Corrigall \& Trainor, 2011; Dyer, 2011; Iwasaki et al., 2013; Patscheke et al., 2018). Iwasaki et al. (2013) found that the integration of lyrical musicduring reading instruction led to a year's growth in the reading levels of all but one participant. It was noted that "because of the motivational nature of singing, students were willing to engage in repeated reading of the songs throughout the week until all students could read/sing the song fluently" (Iwasaki et al., 2013, p. 140). These findings revealthe use of music as an instructional strategy, as well as its correlation to academic motivation and performance.

Cole and Boykin (2008) focused on the use of music interventions with African American youth and its correlation to children's story recall. Even though the intervention proved to be a positive experience, the older students were more responsive to the music and movement interventions that required less active participation. Results indicated that this was likely due to a fear of being judged or embarrassed by their peers (Cole \& Boykin, 2008). Additionally, Corrigall and Trainor (2011) examined word decoding and reading comprehension with students — ages 6 to 9 - who had received music training. Results showed that there was little or no correlation between length of music training and word decoding skills. However, music training significantly increased reading comprehension levels (Corrigall \& Trainor, 2011). In alignment with this notion, Patscheke et al. (2018) focused on the effects of pitch and rhythm training on preschoolers' phonological awareness, a basic building block for fluent reading. Both the rhythm-and pitchtrained groups showed improvement in phonological awareness; however, results from the rhythm group were not statistically significant (Patscheke et al., 2018).

\subsubsection{Attention.}

In addition to cognition, many studies have concluded that music integration elicits positive effects on concentration in students of all ages (Dewi et al., 2015; Rickard et al., 2010; Sandberg et al., 2013). For example, one study examined two first-grade students and found that, "when students were off-task, the teacher would sing a song, chant or rhyme, which helped the students refocus and complete their work" (Sandberg et al., 2013, p.9). Furthermore, Rickard et al.(2010) examined the effects of music training and verbal memory on children's attention whose mean age was 8.62 years, and noted that attention in the classroom improved throughout the duration of the study when compared with the control group. Similarly, another study revealed that third-grade children who were exposed to music interventions during the school day had an $11.7 \%$ increase in attention compared to students who did not receive the intervention (Dewi et al., 2015). For younger children, music has also been noted as an activity that helps to foster the attention necessary for school readiness (Flohr et al., 2000). 


\subsection{Benefits of movement integration}

Similar to music, there are several different movement interventions for the classroom that have been examined. These interventions include calming movements such as mindfulness and yoga, brain breaks, and physical activities that are incorporated into the curriculum to teach or reinforce an academic concept or skill. In programs such as Take 10!, teachers utilize physical activity as a way to re-energize students after intense or extensive instruction (Take 10!, 2015). Calming movement strategies such as yoga or meditation are aimed at refocusing attention back to the curriculum, while small bouts of low-to-moderate physical activity integration may re-energize students while simultaneously priming the brain for learning.

\subsubsection{Academic achievement.}

The potential benefits of movement integration on not only academic motivation, but also academic performance have been a focal point in the research. Reed et al. (2010) found that, among a group of third-grade students, "aerobically trained or physically active participants performed significantly better on fluid intelligence tasks than untrained or inactive participants" (p. 348). Mullender-Wijnsma et al. (2015) also examined the effects of physical activity on academic performance. The conclusions were drawn through scrutiny of both mathematics and reading skills, which was unique to this particular study. However, the researchers did not rely entirely on test results, as they also collected teacher observations of the students' time-on-task. Findings revealed that third-grade students performed significantly higher on both the reading and mathematics assessments when compared to their peers in the control classes, and displayed on-task behaviors that were above 70\% during the intervention lessons (Mullender-Wijnsma et al., 2015).

\subsubsection{Attention.}

Another largely explored facet of research related to movement integration in the classroom is its impact on attention. Sandberg et al. (2013) found that integrating movement into spelling, sight words, or literacy concepts re-energized the students, increased attention to the task, and helped concentration. Another study examined boys between the ages of eight and thirteen with attention deficit hyperactivity (ADHD) to determine if movement, specifically yoga, could help reduce the increasing number of children receiving pharmaceutical interventions as the solitary treatment for their hyperactivity (Jensen \& Kenny, 2004). Results for the experimental group showed positive trends on ten of the Conners' Parent Rating Scales, while the control group showed positive trends in six of the specified categories.

\subsection{Deficiency of music and movement intervention research}

Separate music and movement integration strategies and programs in the general education classroom have revealed encouraging results on student achievement, motivation, and engagement. However, minimal research studies have been conducted to determine the potential benefits of incorporating both music and movement interventions in the elementary classroom simultaneously. A majority of studies that have examined both music and movement simultaneously as an intervention focused solely on the impact it had on ELA (language development) and student engagement in the classroom.

\subsubsection{Impact of music and movement on language.}

Yazejian and Peisner-Feinber (2009)examined the effects of a dually integrated program on preschool children's language skills. Participants were selected from a Head Start preschool program, which presents its own challenges, as it limits the ability of the researchers to determine whether the outcomes were a result of the intervention or the preschool itself. Despite this limitation, the study still bodes useful because it is one of the few that integrates both music and movement. The program implemented at the school featured a sequenced curriculum that was taught by a music specialist twice a week for thirty minutes throughout the school year. Findings of this study indicated that the students receiving the intervention made significant gains in their communication skills compared to the control group(Yazejian \& Peisner-Feinber, 2009).

\subsubsection{Impact of music and movement on behavioral engagement.}

Sandberg et al. (2013) focused specifically on the impact that music and movement had on student engagement. Participants were two students whose native language was Spanish. The first student was observed for twenty-five days and the second for twenty-two days, due to withdrawing from the school. The students were described as struggling with behavior, attention, engagement, and motivation. Methods utilized included time sampling and daily interviews to support their claim that music and movement is a highly useful tool for improving children's behavior. Results of the study indicated a general increase in positive behaviors and a decrease in negative behaviors, as well as increased attention and engagement in classroom activities (Sandberg et al., 2013). 


\subsection{Music and movement as interventions for classroom transitions}

As aforementioned, most research studies have focused on music and movement as interventions for increasing students' attention, behavior, and/or improving academic achievement in ELA or mathematics. However, minimal research studies have focused on music and movement as a method for signaling the start or finish of daily routines, more commonly known as transitions. It is even less common to find literature centering on music and movement strategies utilized as the transitions themselves. Despite this deficiency, transitions have the ability to positively or negatively affect instruction and are described in the literature as indicators of both teachers' effectiveness and students' success (Johns et al., 2008). When implemented effectively in the classroom, transitions facilitate a smooth shift from one lesson or activity to another. Conversely, when transitions are ineffective they may become a major source of off-task time in the classroom (Johns et al., 2008). Consequently, ineffective transitions can lead to a significant loss of instructional time, limiting students' learning.

\subsubsection{Music and transitions.}

Register and Humpal (2007) examined three case studies that used music as a tool to facilitate transitions throughout the school day. In the first case study, a music therapist used transition songs to encourage a toddler class to continue to the next activity. Results indicated that "before the intervention, it took students 180 seconds to move to the next task after instructions were given, and after the intervention, the length of time decreased to 80 seconds" (Register \& Humpal, 2007, p. 27). In the second case study, researchers measured the amount of time needed for kindergarten children to put away their supplies and the number of verbal prompts or redirections in order to be ready for the next activity. Findings revealed "the entire group responded more quickly to directives issued in music than to directives given verbally" (Register \& Humpal, 2007, p. 29). In the third case study, a class of pre-kindergarten students was measured before and after a finger cymbal and goodbye song was introduced. After six weeks, the amount of required time had decreased to less than 35 seconds (Register \& Humpal, 2007). This decrease in time implies that music integration could be an effective tool for promoting effectively managed classroom transitions.

\subsubsection{Movement and transitions.}

Bobe et al. (2014) evaluated the perceptions and impact of implementing segments of a "Brain Breaks" exercise DVD in elementary classrooms. The authors define brain breaks as short segments of physical activity, and they encouraged the classroom teachers to play portions of the DVD at least once per week throughout the school day when the students began to grow restless. Results indicated that most teachers increased the use of brain breaks to two to three times per week, and approximately $90 \%$ of the 43 teachers planned to continue its use following the conclusion of the study (Bobe et al., 2014). Therefore, it was concluded that brain breaks were an effective method for increasing physical activity in the elementary classroom because students were excited and engaged during their implementation. However, the DVD was not specifically implemented during transition times, which reiterates the need for the present study to address the effectiveness of music and movement as an intervention to aid in increasing transition times and student engagement.

\subsection{Theoretical framework}

In relation to music integration, the underpinnings of this study emanate from the notion that arousal and mood affect learning (Russell, 1980). The arousal-mood-hypothesis acknowledges that music has the ability to act as a mediator that positively affects the way one feels and subsequently how one engages behaviorally and academically in the classroom (Husain et al., 2002). In addition to music integration, this study also examined movement integration through the lens of constructivism, as an active learning theory (Wadsworth, 1971). Thus, supporting the idea that the use of movement in the classroom can be employed to construct meaning through an active learning process that utilizes multiple modalities (Gardner, 1983) and has the ability to change learning outcomes by supporting all learners' needs. Supporting this theory, Gabler-Halle et al. (1993) found that the greatest degree of change is found directly following physical activity integration. Thus, this notion supports the method of measuring transition time after the physical activity intervention within the present study in addition to the academic engagement levels of students measured observationally during all intervention phases.

\subsection{Purpose of the study}

Transitions account for a significant portion of lost instructional time during the school day (Banerjee \& Horn, 2013; Johns et al., 2008). Thus, the purpose of this study was to examine the impact of music and movement as interventions on transition times, student engagement, and behavior in a first-grade classroom. Accordingly, this study measured the length of transition time with and without music and movement interventions to determine if the strategies increased or decreased both transition and instructional time. Additionally, any changes in the duration of student engagement and 
behaviors relating to body language and focus as a result of the music and movement interventions were examined. The following research questions guided the present study:

1. Do music, movement, or music and movement interventions increase or decrease the length of time it takes for students to transition to their next task at the beginning of the school day and following recess?

2. What effect do music, movement, or music and movement interventions have on specific student behaviors in the areas of body language and focus?

3. Does student engagement in the task increase, decrease, or remain stagnant following a music, movement, or music and movement intervention?

\section{Methods}

The present study took place in a first-grade classroom at an elementary school in northwest Mississippi during Fall 2018. Participants $(n=21)$ were selected through non-probability purposive sampling. Ages of the participants ranged from six to nine, and all came from varying socioeconomic backgrounds, races, and academic levels. Demographics of the participants were as follows: White (42.9\%), African American (52.4\%), and Hispanic (5\%). The male to female ratio was 13:8. Based on standardized test scores, the participants' ability levels spanned from below grade level in mathematics and reading to on target.

\subsection{Procedures}

\subsubsection{Design.}

Prior to the study, consent was obtained from all participants, including the teacher, the school's principal, as well as approval from the University's Institutional Review Board. Written consent was also acquired from each child's parent. An experimental multi-phase approach was employed during the study wherein observational data were collected for eight weeks - September-November 2018. The four phases of the study were categorized as follows: (a) baseline data collection, (b) music interventions, (c) movement interventions, and (d) music and movement interventions. The first two weeks were comprised of an observational period intended to measure how long it took the students to transition from one activity to the next at the beginning of the school day and following recess. This phase helped to establish baseline data. The next two weeks the teacher implemented music interventions, one week of classical music followed by one week of popular music, such as Disney children's songs. Then followed two weeks of movement interventions, which were divided into one week of simple stretches and another week comprised of common children's games, such as Simon says, red rover, and red light green light. The final two weeks, interventions were implemented that combined both music and movement through song and dance. Examples of this include GoNoodle and Jack Hartmann videos, as well as activities, such as choreographing individual or group dances to a song about the four seasons or the water cycle. All interventions were three to five minutes in length and implemented on Mondays and Wednesdays - once in the morning and once in the afternoon during transition times.

\subsubsection{Measures.}

Following the interventions, the length of time it took students to transition to the next academic task or assignment, demonstrated by the majority of students being engaged in the lesson was measured. For the purpose of this study, engagement was defined as students listening quietly to the speaker, following directions appropriately, and participating when called upon. In a classroom of 21 students, the majority was determined to be 17 or more students showing engagement. The number 17 was derived as a result of calculating the mean number of students, 10.5, and adjusting up for one standard deviation, 6.055, which totaled 17 students. As the activity or assignment progressed, the presence or absence of certain behaviors listed on a student engagement checklist adapted from behaviors discussed in the Handbook of Research on Student Engagement as indicators of both focus and engagement were noted(Christenson et al., 2012) (See Appendix A). The checklist measured the start and stop times of the intervention, the start and stop times of the instruction for the next task or activity, and the length of time that the majority of students showed engagement in the lesson. The second section of the chart was separated into two subsections based on body language and focus. Body language was measured on the following factors: eyes on speaker, appropriate posture, nonverbal response, and body containment. The focus section of the chart measured whether the participants remained in their assigned area, followed classroom procedures, self-started, and problem solved to get help if needed. Each of these behaviors was categorized as either not applicable, non-existent, inconsistent, or consistent.

\subsection{Data Analysis}

Data from each of the four phases were averaged separately to determine the length of time that the majority of students remained engaged in the academic task or activity that followed each intervention. This data was placed into a bar graph that depicts the statistical data from each intervention phase, allowing the researcher to concisely present the total length of time of engagement for the four stages of the study. 
The second data set from each observational period was also converted into a table that provides a visual of which behaviors were categorized as not applicable, non-existent, inconsistent, and consistent throughout each phase of the study. The bar graph and table were analyzed in order to determine the effectiveness of the interventions on decreasing the time it took for students to transition from non-instructional portions of the school day into structured, academic activities with and without music and movement.

\section{Results}

Findings were separated into four different visual representations. Two bar graphs that reveal the mean transition time and the mean duration of engagement following each intervention throughout the four phases of the study and two tables documenting the prevalence of specific behaviors associated with body language and focus.

\subsection{Transition times}

\subsubsection{Music interventions.}

At baseline, students' mean transition time was three minutes $(S D=.82)$ in the morning and three minutes and fifteen seconds $(S D=.96)$ following recess. After music interventions were employed, morning transitions decreased to two minutes and thirty seconds $(S D=1.73)$. However, the mean afternoon transition time remained the same at three minutes and fifteen seconds $(S D=1.7)$. Even though the data did not reveal any change in the mean afternoon transition time, the mean morning transition time decreased by $16.7 \%$ following the music interventions (See Figure 1).

\subsubsection{Movement interventions.}

Morning transitions decreased from three minutes to a mean of one minute and seven and a half seconds $(S D=0.63)$ following the movement interventions. This change equates to a $62.5 \%$ decrease in the length of time that it took students to transition in the morning. The mean afternoon transition also decreased from three minutes and fifteen seconds to one minute and fifteen seconds, equating to a $61.5 \%$ decrease $(S D=0.5)$ (See Figure 1).

\subsubsection{Music and movement interventions.}

When music and movement interventions were utilized, the mean morning transition time decreased from three minutes, to forty-five seconds $(S D=0.29)$. This change equates to a $75 \%$ decreasein transition time. Furthermore, the mean afternoon transition time decreased from three minutes and fifteen seconds to fifty-two and a half seconds $(S D=$ 0.25). The implementation of music and movement interventions led to an overall $73.1 \%$ decrease in the length of mean afternoon transition time (See Figure 1).

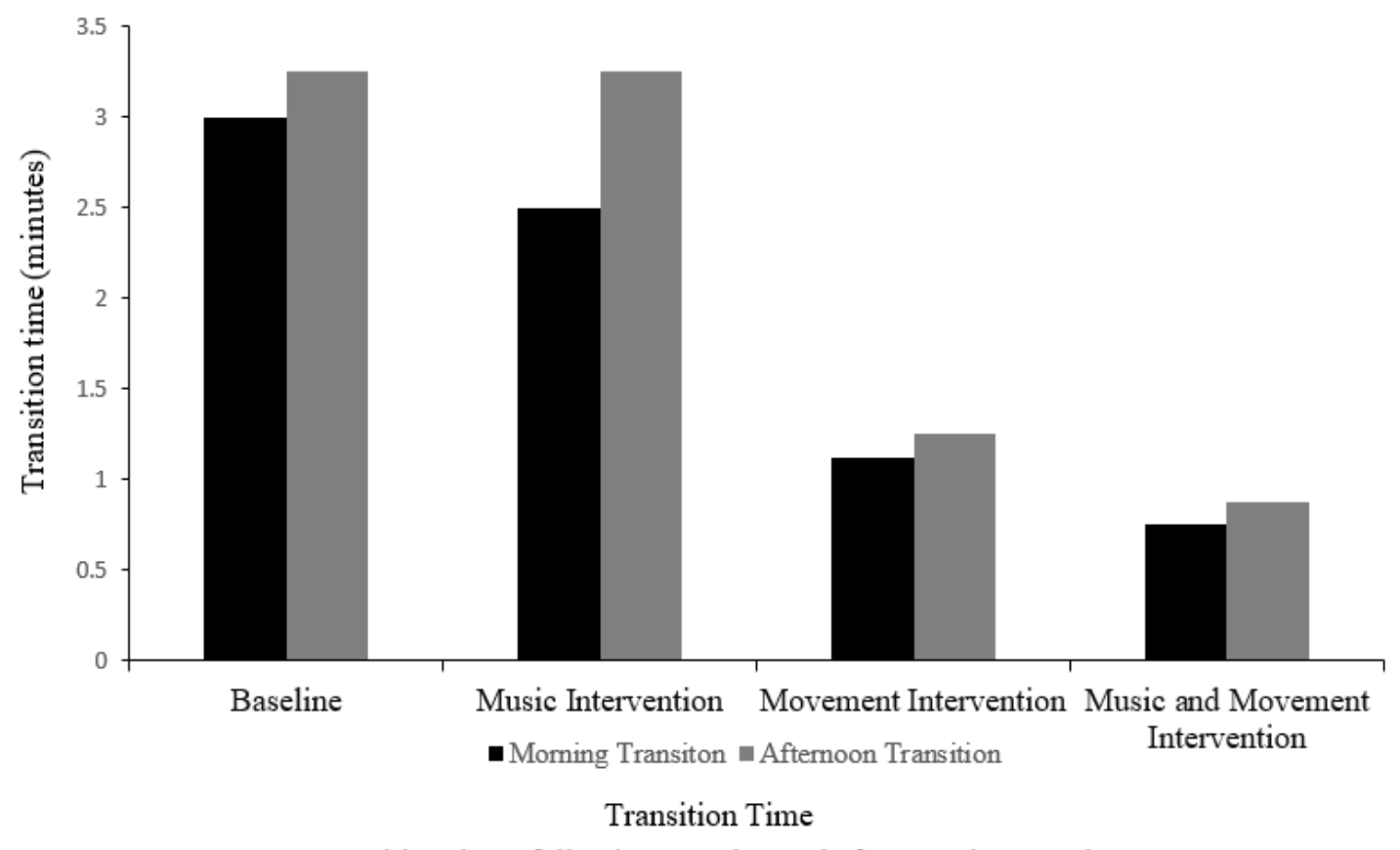

Figure 1. Average transition times following morning and afternoon interventions. 


\subsection{Engagement}

\subsubsection{Music interventions.}

Baseline data revealed that on average students remained engaged in their task at the beginning of the day for four minutes and thirty seconds $(S D=1.29)$. Following the implementation of music interventions during transitions, the average time of engagement in the morning increased to seven minutes and fifteen seconds $(S D=2.99)$. This equated to a $61.1 \%$ increase. During the baseline phase of the study, the mean time of engagement in the afternoon was five minutes and fifteen seconds $(S D=1.29)$, which also increased following the music interventions as a transition to nine minutes and forty-five seconds $(S D=1.71)$. This change equates to an overall increase of $85.7 \%$ (See Figure 2$)$.

\subsubsection{Movement interventions.}

When compared to the baseline data, the mean length of time that students remained engaged following movement interventions utilized as transitions in the morning increased from four minutes and thirty seconds to thirteen minutes and twenty-two and a half seconds $(S D=4.11)$. This reveals an increase of $197.2 \%$. In regard to the movement interventions conducted following recess as a transition, the mean length of engagement increased again, from baseline of five minutes and fifteen seconds to twelve minutes $(S D=3.74)$. This equated to a $128.6 \%$ increase in the length of time that students remained engaged following the intervention (See Figure 2).

\subsubsection{Music and movement interventions.}

Data from this phase of the study also indicated an increase in the mean length of student engagement following both morning and afternoon interventions as transitions. After music and movement interventions as transitions were utilized in the morning, engagement increased from four minutes and thirty seconds at baseline to twelve minutes and thirty seconds $(S D=2.12)$. This change is equal to a $177.8 \%$ increase in the length of engagement following music and movement interventions. Furthermore, the length of afternoon engagement also increased five minutes and fifteen seconds at baseline to fourteen minutes and seven and a half seconds $(S D=3.52)$. Overall, this equated to a $169 \%$ change (See Figure 2).

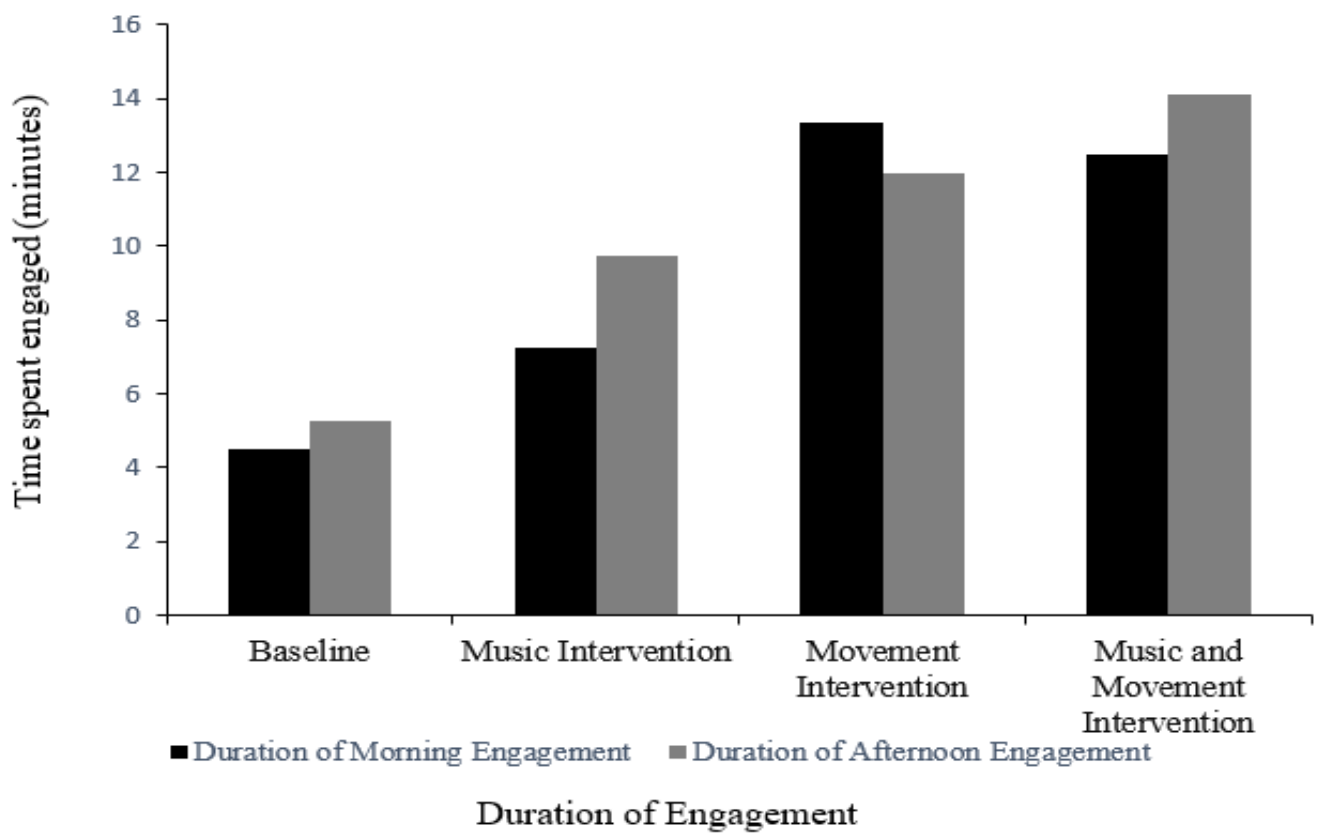

Figure 2. Average length of engagement following morning and afternoon interventions.

\subsubsection{Body language.}

All four behaviors in Table 1 improved across each phase of the study. More specifically, eyes on speaker improved from being measured as consistent one time in the initial phase of the study to five, seven, and eight times consistent in the subsequent phases. Appropriate posture also improved, as it increased from zero times consistent in the baseline phase to two, seven, and eight times consistent in the music, movement, and music and movement interventions. 
Furthermore, nonverbal response also improved from zero times consistent to four, eight, and eight times consistent. The final behavioral measure was body containment, which followed the same trend as the previous three behaviors, as it increased from one at baseline to two, eight, and eight throughout the study (See Table 1).

Table 1

Body Language Consistency

\begin{tabular}{|c|c|c|c|c|}
\hline & $\begin{array}{l}\text { EYES ON } \\
\text { SPEAKER }\end{array}$ & $\begin{array}{l}\text { APPROPRIATE } \\
\text { POSTURE }\end{array}$ & $\begin{array}{c}\text { NONVERBAL } \\
\text { RESPONSE }\end{array}$ & $\begin{array}{c}\text { BODY IS } \\
\text { CONTAINED }\end{array}$ \\
\hline \multicolumn{5}{|l|}{ BASELINE } \\
\hline Consistent & 1 & 0 & 0 & 1 \\
\hline Inconsistent & 7 & 8 & 6 & 7 \\
\hline Non-existent & 0 & 0 & 1 & 0 \\
\hline Not Applicable & 0 & 0 & 1 & 0 \\
\hline \multicolumn{5}{|l|}{$\begin{array}{l}\text { MUSIC } \\
\text { INTERVENTION }\end{array}$} \\
\hline Consistent & 5 & 2 & 4 & 2 \\
\hline Inconsistent & 1 & 3 & 1 & 4 \\
\hline Non-Existent & 0 & 0 & 0 & 0 \\
\hline Not Applicable & 2 & 3 & 3 & 2 \\
\hline \multicolumn{5}{|l|}{$\begin{array}{l}\text { MOVEMENT } \\
\text { INTERVENTION }\end{array}$} \\
\hline Consistent & 7 & 7 & 8 & 8 \\
\hline Inconsistent & 0 & 1 & 0 & 0 \\
\hline Non-existent & 0 & 0 & 0 & 0 \\
\hline Not Applicable & 1 & 0 & 0 & 0 \\
\hline \multicolumn{5}{|l|}{$\begin{array}{l}\text { MUSIC AND } \\
\text { MOVEMENT } \\
\text { INTERVENTION }\end{array}$} \\
\hline Consistent & 8 & 8 & 8 & 8 \\
\hline Inconsistent & 0 & 0 & 0 & 0 \\
\hline Non-Existent & 0 & 0 & 0 & 0 \\
\hline Not Applicable & 0 & 0 & 0 & 0 \\
\hline
\end{tabular}

Findings from the focus consistency table also revealed a positive trend across all four phases. The consistency of remaining in the assigned area across all four phases increased from six to eight, eight, and eight respectively. Furthermore, following classroom procedures increased in the same pattern, being observed as consistent one time in the baseline phase to six, eight, and eight throughout the subsequent phases of the study. The students' ability to selfstart also showed improvement, initially being observed as consistent zero times, to three times throughout the study. The final behavior, problem solving to get help if needed, also became more consistent as the study progressed. During the baseline phase, this behavior was measured as consistent zero times and it remained at zero throughout the music interventions. However, positive improvements were seen in the movement and music and movement interventions as this behavior consistent one and then two times respectively (See Table 2). 
Table 2

Focus Consistency

\begin{tabular}{|c|c|c|c|c|}
\hline & $\begin{array}{c}\text { REMAINING } \\
\text { IN ASSIGNED } \\
\text { AREA }\end{array}$ & $\begin{array}{l}\text { FOLLOWING } \\
\text { CLASSROOM } \\
\text { PROCEDURES }\end{array}$ & $\begin{array}{c}\text { SELF- } \\
\text { STARTING }\end{array}$ & $\begin{array}{c}\text { PROBLEM } \\
\text { SOLVING TO } \\
\text { GET HELP IF } \\
\text { NEEDED }\end{array}$ \\
\hline \multicolumn{5}{|l|}{ BASELINE } \\
\hline Consistent & 6 & 1 & 0 & 0 \\
\hline Inconsistent & 2 & 7 & 2 & 6 \\
\hline Non-existent & 0 & 0 & 4 & 0 \\
\hline Not Applicable & 0 & 0 & 2 & 2 \\
\hline \multicolumn{5}{|l|}{$\begin{array}{l}\text { MUSIC } \\
\text { INTERVENTION }\end{array}$} \\
\hline Consistent & 8 & 6 & 3 & 0 \\
\hline Inconsistent & 0 & 2 & 4 & 5 \\
\hline Non-Existent & 0 & 0 & 0 & 0 \\
\hline Not Applicable & 0 & 0 & 1 & 3 \\
\hline \multicolumn{5}{|l|}{$\begin{array}{l}\text { MOVEMENT } \\
\text { INTERVENTION }\end{array}$} \\
\hline Consistent & 8 & 8 & 3 & 1 \\
\hline Inconsistent & 0 & 0 & 0 & 1 \\
\hline Non-existent & 0 & 0 & 0 & 0 \\
\hline Not Applicable & 0 & 0 & 5 & 6 \\
\hline \multicolumn{5}{|l|}{$\begin{array}{l}\text { MUSIC AND } \\
\text { MOVEMENT } \\
\text { INTERVENTION }\end{array}$} \\
\hline Consistent & 8 & 8 & 3 & 2 \\
\hline Inconsistent & 0 & 0 & 1 & 2 \\
\hline Non-Existent & 0 & 0 & 0 & 0 \\
\hline Not Applicable & 0 & 0 & 4 & 4 \\
\hline
\end{tabular}

\section{Discussion}

The current research on music and movement interventions in the classroom indicates that students' attention and academic performance improve when such integrated activities are utilized (Register \& Humpal, 2007; Sandberg et al., 2013). Even though research studies have shown positive outcomes, there is a lack of research on music and movement as interventions for improving transition times and student engagement in the classroom. Additionally, barriers of implementation for teachers were found to be a lack of time and knowledge on how to effectively implement music and movement in the classroom. Thus, the present study not only addressed the research-based barriers by implementing music and movement during a time of the day that usually "takes up time," but it also aimed to fill a significant gap in the literature by examining and differentiating between music, movement, and music and movement used as interventions during transitions.

Regarding the usefulness of music interventions as transitions, results of the present study were similar to those of previous studies that advocate for their use as tools to aid attention and engagement in the classroom (Iwasaki et al., 2013; Rickard et al., 2010; Sandberg et al., 2013). Data from the present study refutes the notion of Salamé and Baddeley (1989) that music decreases attention. In fact, when both music and movement were utilized as a transition tool, attention as measured in minutes increased the most, while body language and focus as measured by behaviors also improved. 
Findings regarding movement interventions in the present study were also congruent with the research on movement in the classroom that has proved beneficial for aiding attention-deficit and hyperactivity disorders as well as academic performance and motivation (Grönlund et al., 2005; Jensen \& Kenny, 2004; Mullender-Wijnsma et al., 2015; Vazou et al., 2012).

Because there is such limited research regarding the feasibility and impact of music and movement interventions as transitions in the classroom, the results of this study are noteworthy. Findings of this study indicate that not only are music and movement interventions useful tools to use in the classroom to increase instructional effectiveness, but when combined, music and movement interventions produced even more positive results in the areas of both body language and focus. The connection between the improved behaviors demonstrated throughout the different phases of this study should not be overlooked, as they directly relate to a more effective classroom. Additionally, this study's findings not only align with previous research, but also reached beyond those boundaries to differentiate between the effects of music, movement, and music and movement interventions on students' transition times, engagement, and behavior. By addressing the interventions during transition times, which to our knowledge is an under-researched topic, we were able to address teachers' barriers of time and in fact increase transition times and engagement across all phases of the study.

\subsection{Limitations}

There are several limitations of this study that are important to consider. First, the researchers were unable to guarantee what subject was taught following the implementation of each intervention. Although reading was most often taught in the morning and writing taught in the afternoon, there were occasions in which math or spelling was taught in place of one of the aforementioned subjects. These changes were most often the result of an upcoming test that required the classroom teacher to adequately prepare and review with her students. A second limitation is that the research was conducted with an entire class of first-grade students, so the gender ratio was not equal. There were five more boys in the class than girls, which could have potentially impacted which interventions were most beneficial to the students. Another limitation of this study was the change in the number of participants. Due to illness and progress monitoring, the number of student participants fluctuated between 17 and 21 throughout the course of the study. This may have led to an over inflation of the success of specific types of interventions, but it may have also led to an underestimation of the benefits produced by these same interventions. A fourth limitation revolves around the success of the music and movement interventions and the sequence in which the interventions occurred. As the study progressed, the interventions proved to be more successful, so it is worth noting that the significant success of the music and movement interventions could have been influenced by the students' continuous exposure to the various types of interventions performed in the study.

\subsection{Future research}

Future research should focus on similar types of interventions; however, it would be useful to analyze data based on gender to see if there are any differences in the success of certain interventions that could be attributed to this specific variable. Furthermore, it would be beneficial if future studies tested the effects of music, movement, and music and movement interventions separately on students attending different schools to account for any results that might occur from students growing accustomed to the interventions. Additionally, utilizing a control group to compare amongst the various groups would also be beneficial.

\subsection{Conclusion}

The beneficial nature of music and movement interventions in aiding the educational experience of both teachers and students emerged throughout this study. Effective transitions led to more engaged students who exhibited positive behaviors. Teachers often spend less time offering corrections and more time on instruction when behaviors improve. Ultimately, music and movement as interventions during transitions can foster positive behavioral and instructional outcomes and should be explored even further, as this study revealed its impact on one of the most valuable assets teachers and students have in their possession, time.

\section{References}

Banerjee, R. \& Horn, E. (2013). Supporting classroom transitions between daily routines: $\quad$ Strategies and tips. Young Exceptional Children, 16(2), 3-14.

Benes, S., Finn, K. E., Sullivan, C., \& Yan, Z. (2016). Teachers' perceptions of using movement in the classroom. The Physical Educator, 73(1), 110-135. doi.org/10.18666/TPE-2016-V73-I15316 
Bobe, G., Perera, T., Frei, S., \&Frei, B. (2014). Brain breaks: Physical activity in the classroom for elementary school children. Journal of Nutrition Education and Behavior, 46(4S), S141.

Christenson, S. L., Reschly, A. L.,\& Wylie, C. (Eds.). (2012). Handbook of Research on Student Engagement. New York, NY: Springer.

Cole, J.M., \& Boykin, W.A. (2008). Examining culturally structured learning environments with different types of music-linked movement opportunity. Journal of Black Psychology 34(3), 331-355.

Colwell, C.M. (2008). Integration of music and core academic objectives in the K-12 curriculum: Perceptions of music and classroom teachers. Update: Applications of Research in Music Education, 26(2), 33-41. doi:10.1177/8755123308317954

Corrigall, K.A., \& Trainor, L. (2011). Associations between length of music training and reading skills in children. Music Perception, 29(2), 147-155.

David, J. L. (2011). Research says ... high-stakes testing narrows the curriculum. Educational Leadership, 68(6), 7880. doi:10.1111/j.1749-6632.2009.04769.x

Dewi, E. K., Rusmawati, D., \& Ratnaningsih, I. Z. (2015). The effect of music and motoric movement intervention to increase attention among elementary school students in Semarang central Java. Procedia Environmental Sciences, 23, 179-185.

Dyer, J.L. (2011). Musical thought: Using music to enhance literacy instruction. Illinois Reading Council Journal, 39(4), 3-9.

Flohr, J. W., Miller, D.C., \& deBeus, R. (2000). EEG studies with young children. Music Educators Journal, 87(2), 2832. https://doi.org/10.2307/3399645

Fortin, J. (2013). Integrating music into Samoan primary schools: Teachers' perceptions and potential benefits. Independent Study Project (ISP) Collection. 1713. https://digitalcollections.sit.edu/isp_collection/1713

Gabler-Halle D., Halle J. W., \&Chung Y. B. (1993). The effects of aerobic exercise on psychological and behavioral variables of individuals with developmental disabilities: A critical review. Research in Developmental Disabilities, 14(5), 359-386. https://doi.org/10.1016/0891-4222(93)900009-9

Gardner, H. (1983). Frames of Mind. New York, NY: Basic Books.

Grönlund, E., Renck, B., \& Weibull., J. (2005). Dance/movement therapy as an alternative treatment for young boys diagnosed as ADHD: A pilot study. American Journal of Dance Therapy, 27(2), 63-85.

Husain, G., Thompson, W. F., \& Schellenberg, E. G. (2002). Effects of musical tempo and mode on arousal, mood, and spatial abilities. Music Perceptions, 20(2), 151-171. 10.1525/mp.2002.20.2.151

Iwasaki, B., Rasinski, T., Yildirim, K., \& Zimmerman, B.S. (2013). Let's bring back the magic of song for teaching reading. The Reading Teacher, 67(2), 137-141.

Jensen, P.S., \& Kenny, D.T. (2004). The effects of yoga on the attention and behavior of boys with AttentionDeficit/hyperactivity Disorder. Journal of Attention Disorders, 7(4), 205-216.

Johns, B.H., Crowley, E.P., \& Guetzloe, E. (2008). Engaged time in the classroom. Focus on Exceptional Children, 4l(4), 1-8.

Mullender-Wijnsma, M.J., Hartman, E., de Greeff, J.W., Bosker, R.J., Doolaard, S., \&Visscher, C. (2015). Improving academic performance of school-age children by physical activity in the classroom: 1-Year program evaluation. Journal of School Health, 85(6), 365-371.

Myrianthopoulos, E. (2015). Improving pre-service teachers' preparation to integrate music and movement in early childhood classrooms. New York: Bank Street College of Education. Retrieved from http://educate.bankstreet.edu/independent-studies/44

Nelson, H. (2013). Testing More, Teaching Less What America's Obsession with Student Testing Costs in Money and Lost Instructional Time. Retrieved from https://www.aft.org/sites/default/files/news/testingmore2013.pdf

Patall, E., Cooper H., \& Allen, A.(2010).Extending the school day or school year. Review of Educational Research, 80(3), 401-436.

Parks, M., Solomon, M., \& Lee, A. (2007). Understanding classroom teacher's perceptions of integrating physical activity: A collective efficacy perspective. Journal of Research in Childhood Education, 21(3), 316-328.

Patscheke, H., Degé, F., \&Schwarzer, G. (2018). The effects of training in rhythm and pitch on phonological awareness in four-to six-year-old children. Psychology of Music, 1-16.

Reed, J.A., Einstein, G., Hahn, E., Hooker, S.P., Gross, V.P., \& Kravitz, J. (2010). Examining the impact of integrating physical activity on fluid intelligence and academic performance in an elementary school setting: A preliminary investigation. Journal of Physical Activity and Health, 7(3), 343-351. 
Register, D. \& Humpal, M. (2007). Using musical transitions in early childhood classrooms: Three case examples. Music Therapy Perspectives, 25(1), 25-31.

Rickard, N.S., Vasquez, J.T., Murphy, F., Gill, A., \& Toukhsati, S.R. (2010). Benefits of a classroom based instrumental music program on verbal memory of primary school children: A longitudinal study. Australian Journal of Music Education, 2010(1), 36-47.

Russell, J. A. (1980). A circumplex model of affect. Journal of Personality and Social Psychology, 39(6), 1161-1178.

Salamé P., \& Baddeley, A. (1989). Effects of background music on phonological short-term memory. The Quarterly Journal of Experimental Psychology, 41A(1), 107-122.

Sandberg, H., Cory, H., \& Kathleen, P. (2013). Increasing engagement through music and movement. Academic Exchange Quarterly, 17(4), 5-11.

Take 10 brings physical activity in the classroom. (2015). Retrieved fromhttp://take10.net

Vazou, S., Gavrilou, P., Mamalaki, E., Papanastasiou, A., \& Sioumala, N. (2012). Doesintegrating physical activity in the elementary school classroom influence academic motivation? International Journal of Sport and Exercise Psychology, 10(4), 251-263.

Wadsworth, B. J. (1971). Piaget's theory of cognitive development: An introduction for students of psychology and education. New York: McKay.

Yazejian, N. \& Peisner-Feibnerg, E. (2009). Effects of a preschool music and movement curriculum on children's language skills. NHSA Dialog, 12(4), 327-341.

\section{Appendix A}

\section{Student Engagement Checklist}

Date of Observation:

Observer:

Type of Task/Assignment:

Number of Students Present During Observation:

Class Being Observed:

Transition Observations:

\begin{tabular}{|l|l|l|}
\hline Intervention: & Start time: & End time: \\
\hline Classroom Instruction: & Start time: & End time: \\
\hline $\begin{array}{l}\text { Majority of Students show } \\
\text { Engagement: }\end{array}$ & Start time: & End time: \\
\hline
\end{tabular}

Body Language

\begin{tabular}{|l|l|l|l|l|}
\hline & Consistent & Inconsistent & Non-Existent & Not Applicable \\
\hline Eyes on Speaker & & & & \\
\hline Appropriate Posture & & & & \\
\hline $\begin{array}{l}\text { Nonverbal } \\
\text { Response }\end{array}$ & & & & \\
\hline Body is Contained & & & & \\
\hline
\end{tabular}

\section{Focus}

\begin{tabular}{|l|l|l|l|l|}
\hline & Consistent & Inconsistent & Non-Existent & Not Applicable \\
\hline Remaining in & & & & \\
\hline $\begin{array}{l}\text { Following Classroom } \\
\text { Procedures }\end{array}$ & & & & \\
\hline Self-Starting & & & & \\
\hline $\begin{array}{l}\text { Problem Solving to } \\
\text { get Help if Needed }\end{array}$ & & & & \\
\hline
\end{tabular}

